\title{
Application of digital technologies in the training of lawyers for the business sector
}

\author{
Ekaterina Enkova*, Inna Ershova, and Elena Trofimova \\ Kutafin Moscow State Law University (MSAL), Moscow, Russia
}

\begin{abstract}
The purpose of the study is to determine the effectiveness of the implementation of digital resources in the university's educational process to train business lawyers in demand in the digital society, including in the context of the covid-19 pandemic. The method of analysis and sociological method were used as the main ones. The main result of the study is that the fruitful impact of digital technologies used in the educational process on the formation of key competencies of the digital economy in lawyers for business is proved. Conclusions. Using online technologies in educational activities directly depends on the level of digital literacy of university teachers. With the help of sociological research, students' preferences concerning the digital technologies used during distance learning were revealed. The role of information and communication technologies in the process of formation of the individual educational trajectory of undergraduates, in particular, building a personal development trajectory for people with disabilities.
\end{abstract}

\section{Introduction}

Among the most important transformations of the 21 st-century education is, undoubtedly, its digitalization. This was largely facilitated by the overall course of the digitalization of the economy outlined in 2018 and supported by the national program [1]. Thanks to national projects, many countries - France, Ireland, Finland, South Korea, Turkey, China, India - have achieved tremendous results in digital education [2]. At the same time, the U.S. - a recognized leader in online education earlier than others realized the need to introduce digital technologies in education. As early as 2000 , for example, the final report to the US President and Congress by the Internet-Based Education Commission, The Power of the Internet for Learning: Moving from Promise to Practice (https://www.nyu.edu/classes/jepsen/wbecreport.pdf), called for e-learning to become a central element of national education policy.

Under the influence of this trend in Russia, "digital" educational legislation is gradually formed, and local rule-making is developed. The practice of using digital technologies in pedagogical activities, including the training of lawyers, is accumulated. The obvious impact on the adoption of online technologies in training was the transition of educational organizations in March 2020 to a total distance format, dictated by the covid-19 pandemic.

\footnotetext{
* Corresponding author: enkova.e.e@ yandex.ru
} 
Much of what had been normative modeling and pedagogical experimentation before this event became a reality overnight.

Even though the digitalization of legal education has already been discussed in the scientific literature [3], the professional public still faces many challenges, the solution of which requires scientific understanding and expert discussion.

\section{Study methodology}

The methodological basis of the study consisted of such methods of scientific knowledge as analysis, synthesis, deduction, interpretation, forecasting, and comparativist and sociological methods. In particular, the results of sociological studies conducted by the authors in 2020 "Digitalization of the educational process" and "Distance learning in the period of the spread of coronavirus infection" were interpreted and analyzed.

\section{Results of the study}

\subsection{Digital inclusion: a view through the prism of local regulations}

Domestic legislation grants educational organizations a great deal of freedom in decisionmaking regarding the creation of the university's information and communication digital environment. For example, at the O.E. Kutafin Moscow State Law University (hereinafter also - the University), according to the order dated May 17, 2019, No. 148, which approved the Regulation on electronic information and educational environment (Kutafin Moscow State Law University [MSAL], 2019), the electronic information and educational environment (hereinafter - EIOS) as a system-organized set of information, technical and educational and methodological support in electronic form was formed.

One of the key elements of the EIOS is the University Digital Scientific, Educational and Social Network (DSESN), which is designed to create a person-centered information and communication environment that provides information interaction for all participants of the University educational process, including providing them with publicly available and personalized reference, scientific, educational and social information through services that operate based on applied information systems of the University. The DSESN system provides for the operation of electronic personal accounts, which also allow for the personalization of personal profiles and portfolios, as well as social interaction between participants in the learning process.

In development of this act the Regulation on electronic educational resources (MSAL, 2020) as elements of the University EIOS structure was approved by the Order No. 17 dated January 17, 2020. An electronic educational resource (hereinafter referred to as EER) is a system of teaching and learning materials provided in electronic digital form and ensuring the implementation of e-learning.

The need to regulate the distance learning process in the context of the covid-19 pandemic led to the approval by Order No. 149 of May 6, 2020, of the Regulation on the Use of ELearning and Distance Learning Technologies in the Implementation of Educational Programs (MSAL, 2020). The completion of the process of formation of the local regulatory "digital" environment of the University was marked by the adoption of the Regulations on the organization of the educational process of higher education programs - Bachelor's, Specialist's and Master's degree programs, approved by Order No. 481 (MSAL, 2020) dated November 13, 2020. This act regulates the use of e-learning and distance learning technologies (hereinafter - ELT and DOT) to implement educational programs. 
These local acts created a regulatory framework for applying digital learning technologies at the University, identified the functionality of participants in the educational process and technical services of the university.

\subsection{Piloting digital technologies in the learning process}

The University's digital legal field has proven to be very fertile. It took less than a year for the web technologies outlined on paper to be implemented in the educational process. For example, in the implementation of the educational program of Master's degree "Legal Support of Business (Business Lawyer)" (hereinafter - MP "Business Lawyer"), digital technologies are used to the greatest extent in the course of teaching the following academic disciplines:

- "State regulation and self-regulation of entrepreneurial activity", technologies: Rational Unified Process (RUP), phygital, videoclips, electronic textbook, e-learning, PowerPoint;

- "Entrepreneurship" and "Anticrisis management and bankruptcy", technology: PowerPoint, videoclips, organization of research work of students using the Federal portal of draft regulations (https://regulation.gov.ru/), the Unified Federal Register of legally significant information about the facts of legal entities, individual entrepreneurs and other subjects of economic activity (https://fedresurs.ru/), e-learning;

- "Theory and practice of application of banking legislation", technology: phygital, chatbots, e-learning.

It is the teacher who has the burden of proactively creating or searching for a digital resource, its placement in the distance learning system of the University. It is worth mentioning that for a number of disciplines, which were mastered using e-Learning tools and DOT, the systems of current control and independent certification were also formed using web technologies. As an example, here is the program of current and independent interim certification of students in the academic discipline "State regulation and self-regulation of entrepreneurial activity" for the 2020 set with regard to the level of development of basic competencies of a business lawyer of the digital economy placed in the University EIOS.

The educational literature has also undergone a digital transformation. The authors have prepared a web-textbook on the state regulation of entrepreneurship, which contains hyperlinks to legal acts, Internet sources, fragments of video lectures, interactive workbook, as well as assessment tools in the form of electronic tests. In order to fully integrate it into the educational process, the created electronic educational resource was placed in the EIOS of the University. Through the web-page students have access to all course materials, including the working program of the discipline and web-textbook, they can send the completed tasks to the teacher for review or take electronic tests without leaving the IEOS of the University. The transition from one section of the web tutorial to another can be conditioned on successful completion of the test. The points scored by the students during testing and assignments are reflected in the electronic magazine.

\section{Discussion of results}

In June 2020, the authors conducted a sociological study "Distance learning during the spread of coronavirus infection" with the participation of 76 students of MP Business Law. It should be noted that the methodology of empirical assessment of teaching quality, in which the participants of the learning process become its managers, has positively proven itself and is actively used in the educational environment [4].

Students positively evaluated the formats of teacher-student interaction proposed by the University (47.4\% voted for synchronous online communication, while remote asynchronous interaction was approved by $52.6 \%$ of respondents). 
As for the lecture format, the synchronous webinar lecture leads (50\%), followed by the synchronous lecture/forum (26.3\%), and the asynchronous video lecture leaves the top three with a slight lag $(23.7 \%)$. Practical training in webinar format is seen as the most promising and effective by $64.5 \%$ of respondents against $35.5 \%$ of respondents who chose practical forum training.

It was also important to get students' views on the course elements that would be appropriate to use in the future. Thus, $54,7 \%$ of respondents consider remote consultations before examinations effective; $45,3 \%$ of respondents support video lectures as well as lectures read by teachers in the lecture hall; $44 \%$ of students think that part of the practical training in webinar mode is appropriate; weekly online consultations are useful for $36 \%$ of respondents; $21,3 \%$ of respondents suggest to "make legal" remote laboratory workshops, preliminary passing of exams/exams.

The survey participants outlined some of the challenges of using digital technologies during the distance learning period. The main $70.3 \%$ of respondents indicated a problem of technical nature. In the opinion of $12.5 \%$ of trainees, insufficient qualification of teachers makes communication in "digital" difficult. In this regard, we emphasize again the need to improve the digital literacy of educators: "To develop 21 st-century skills in students, educators must learn to confidently use ICTs and integrate digital literacy with their other professional competencies" [5].

For the successful formation of new information competencies among teachers, it is necessary to implement relevant professional development programs to involve IT industry specialists, who would acquaint students in a popular form with the digital technologies demanded by education, business, and legal practice [6]. Thus, in June 2020, all university teachers became trainees of the similar professional development program "Use of information and communication technologies in the educational activity of a modern university".

During the sociological study "Digitalization of the educational process", in which 121 undergraduate and 44 MP students participated, the authors asked the University students about their preferences in terms of the format of educational literature. None of the undergraduate students wanted a paper-only textbook. Of the undergraduates, only 1 person voted for the traditional format. 27 undergraduate and 5 graduate students $(19.39 \%$ of respondents) are ready to be satisfied with the textbook exclusively in electronic form. The vast majority of respondents (94 undergraduate and 37 graduate students, or $79.39 \%$ ) expressed a desire to have a hardcopy textbook with the ability to access it electronically.

Testing in terms of distance learning has clearly demonstrated the advantage of webtextbook as an opportunity for teachers to use its individual elements for classes, implementing current monitoring, and interim certification. The option of modular preparation of textbook material solves the rapid obsolescence of content inherent in "paperbased" educational literature [7]. New sections can be added, and the text of the textbook can be updated as needed. The experience of working collectively in a single digital environment was also precious for the authors.

\section{Conclusions}

Online technologies, designed in the long term to contribute to the full formation of key competencies of the digital economy in business lawyers, in the current moment have demonstrated their high efficiency in the transition of educational organizations to both the total distance learning and hybrid format due to the covid-19 pandemic. In turn, the harsh conditions of self-isolation catalyzed unlocking the rich potential of digital resources for their rapid and widespread introduction into the learning process. 
For teachers to become active agents of digital technology, they themselves must not only constantly improve their legal and pedagogical knowledge and skills but also improve their digital literacy.

Let us emphasize the important role of information and communication technologies in shaping the individual educational trajectory of students, first and foremost, in the master's program [8]. It is all the more difficult to overestimate the importance of digital resources for building a personal developmental trajectory and, ultimately, for the socialization of persons with disabilities [9]. Regarding the web tutorial, we should note that it is one step to create an online course - an electronic resource of a higher level [10].

The reported study was funded by RFBR according to the research project № 18-29-16081 «Transformation of the conceptual framework for the training of lawyers for business in the digital economy».

\section{References}

1. V. V. Tarakanov, A. O. Inshakova, V. V. Dolinskaya, Studies in Computational Intelligence, 826, 3 (2019)

2. O. N. Smolin, Bulletin of Tyumen State University, Socio-economic and legal research 2(1), 29 (2016)

3. I. V. Ershova, O. A. Tarasenko, E. E. Enkova, N. Kvitsinia, Studies in Computational Intelligence 826, 145 (2019)

4. J. D. Cano-Moreno, J. M. Arenas, V. Sánchez, M. Islán, J. Narbón, Procedia Manufacturing 41, 930 (2019)

5. I. V. Ershova, O. A. Tarasenko, E. E. Enkova, E. V. Trofimova, Advances in Intelligent Systems and Computing 1100 AISC, 139 (2020)

6. N.A. Troitsky, E. V. Trofimova, Legal Education and Science 7, 10 (2020)

7. M. Robb, Nurse Author \& Editor 29(4), 1 (2019)

8. O. A. Tarasenko, Legal Education and Science 12, 3 (2019)

9. L. Kendall, Cogent Education, 3, 1 (2016)

10. M. Crosslin et al., Creating Online Learning Experiences. A Brief Guide to Online Courses, from Small and Private to Massive and Open (2018) 